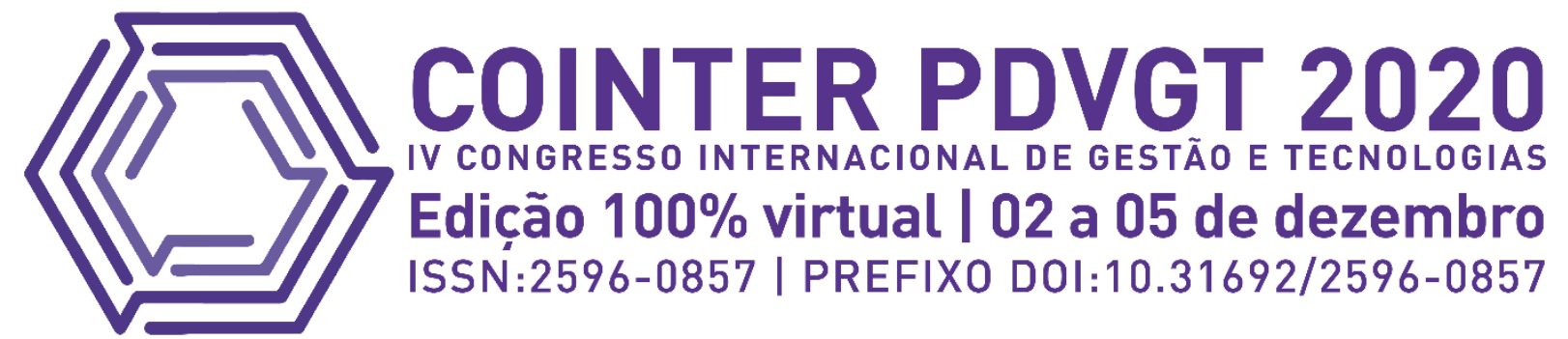

\title{
O LÍDER NO SETOR PÚBLICO: UM ESTUDO SOBRE NOMEAÇÕES DE SECRETÁRIOS MUNICIPAIS
}

\author{
EL LÍDER DEL SECTOR PÚBLICO: ESTUDIO SOBRE LOS NOMBRAMIENTOS \\ DE SECRETARIOS MUNICIPALES
}

\section{THE LEADER IN THE PUBLIC SECTOR: A STUDY ON THE APPOINTMENTS OF MUNICIPAL SECRETARIES}

\author{
Apresentação: Comunicação Oral \\ Max Vinicius Reis Pereira ${ }^{1}$; Claudio Luiz de Oliveira Costa ${ }^{2}$
}

DOI: https://doi.org/10.31692/2596-0857.IVCOINTERPDVGT.0040

\begin{abstract}
RESUMO
A busca cada vez maior por melhores resultados é presente em todas as organizações, ações voltadas para alavancar tais resultados estão sendo tomadas, como implantações de uma abordagem mais gerencial que burocrática e o novo enfoque dado àqueles que dirigem suas equipes de trabalho. No setor público isso não é diferente. A necessidade de melhorar os serviços prestados aos cidadãos tem levado à busca por mais conhecimento, políticas pública mais bem elaboradas e executadas, além de equipes de trabalho mais eficientes, itens que se encontram com a necessidade de líderes eficientes. Portanto, da análise das características de liderança e do padrão de nomeação para cargos de gestão em diferentes áreas da administração pública municipal, este trabalho tem como objetivo geral identificar e classificar estilos e características de liderança que são vistos como essenciais para nomeação de secretários e coordenadores pelo executivo municipal de cidades do Vetor Norte da Região Metropolitana de Belo Horizonte. Para se chegar a esse fim, foram realizadas pesquisas do tipo descritiva, tendo sido os dados e as informações relativos à critérios e preferências dos prefeitos coletados por meio de questionários e analisados à luz da estatística descritiva. Os resultados permitiram constatar que, apesar de vários respondentes defenderem um estilo de liderança democrático, aberto a inovação, participação e desenvolvimento da equipe, ainda há alguns que preferem líderes que mantenham controle de todo o processo, de forma autoritária e dominador. Considerando os dados apurados na pesquisa, pode-se concluir que, para o grupo de prefeitos respondentes, é primordial a presença de um equilíbrio entre os estilos de liderança, ora pendendo para o democrático, ora para o autocrático, haja vista a necessidade constante de controlar de forma rígida os processos de trabalho, visando um bom serviço, ao mesmo momento que se deve estar aberto às ideias e propostas dos membros da equipe. O profissional que dispõe de características desses dois estilos tende a ser mais bem quisto quando das indicações, seleções e nomeações de secretários e demais cargos de liderança na administração pública municipal.
\end{abstract}

Palavras-Chave: Liderança, Gestão Pública, Organizações Públicas.

\footnotetext{
${ }^{1}$ Especialização em Gestão Pública Municipal, Universidade Federal de São João del-Rei (UFSJ), pereiramax@live.com

${ }^{2}$ Mestre em Administração, Universidade Federal Fluminense (UFF), claudioluiz@id.uff.br
} 


\section{RESUMEN}

La búsqueda creciente de mejores resultados está presente en todas las organizaciones, se están tomando acciones encaminadas a apalancar dichos resultados, como implementaciones de un enfoque más gerencial que burocrático y el nuevo enfoque que se le da a quienes dirigen sus equipos de trabajo. En el sector público, esto no es diferente. La necesidad de mejorar los servicios que se brindan a la ciudadanía ha llevado a la búsqueda de mayor conocimiento, políticas públicas mejor diseñadas y ejecutadas, además de equipos de trabajo más eficientes, elementos que responden a la necesidad de líderes eficientes. Por tanto, a partir del análisis de las características del liderazgo y el patrón de nombramiento de los cargos directivos en las distintas áreas de la administración pública municipal, este trabajo tiene como objetivo general identificar y clasificar los estilos y características de liderazgo que se perciben como fundamentales para el nombramiento de secretarios y coordinadores. por el ejecutivo municipal de ciudades del Vector Norte de la Región Metropolitana de Belo Horizonte. Para lograrlo, se realizó una investigación descriptiva, con datos e información relacionada con los criterios y preferencias de los alcaldes recolectados a través de cuestionarios y analizados a la luz de la estadística descriptiva. Los resultados mostraron que, si bien varios encuestados defienden un estilo de liderazgo democrático, abierto a la innovación, la participación y el desarrollo de equipos, todavía hay quienes prefieren líderes que mantengan el control de todo el proceso, de manera autoritaria y dominante. Considerando los datos obtenidos en la investigación, se puede concluir que, para el grupo de alcaldes encuestados, la presencia de un equilibrio entre los estilos de liderazgo es fundamental, a veces para los democráticos, a veces para los autocráticos, dada la constante necesidad de controlar estrictamente los procesos de trabajo, buscando un buen servicio, al mismo tiempo que hay que estar abierto a las ideas y propuestas de los miembros del equipo. El profesional que tiene características de estos dos estilos tiende a ser más popular cuando se trata de nominaciones, selecciones y nombramientos de secretarios y otros puestos de liderazgo en la administración pública municipal.

Palabras Clave: Liderazgo, Gestión Pública, Organismos Públicos.

\section{ABSTRACT}

The increasing search for better results is present in all organizations, actions aimed at leveraging such results are being taken, as implementations of a more managerial than bureaucratic approach and the new focus given to those who direct their work teams. In the public sector, this is no different. The need to improve the services provided to citizens has led to the search for more knowledge, better designed and executed public policies, in addition to more efficient work teams, items that meet the need for efficient leaders. Therefore, from the analysis of leadership characteristics and the pattern of appointment to management positions in different areas of municipal public administration, this work has the general objective of identifying and classifying leadership styles and characteristics that are seen as essential for the appointment of secretaries and coordinators. By the municipal executive of cities in the North Vector of the Metropolitan Region of Belo Horizonte. To achieve this, descriptive research was carried out, with data and information related to the mayors' criteria and preferences collected through questionnaires and analyzed in the light of descriptive statistics. The results showed that, although several respondents defend a democratic leadership style, open to innovation, participation and team development, there are still some who prefer leaders who maintain control of the entire process, in an authoritarian and dominant manner. Considering the data obtained in the research, it can be concluded that, for the group of respondent mayors, the presence of a balance between leadership styles is essential, sometimes for the democratic, sometimes for the autocratic, given the constant need to strictly control the work processes, aiming at a good service, at the same time that one must be open to the ideas and proposals of the team members. The professional who has characteristics of these two styles tends to be more popular when it comes to nominations, selections and appointments of secretaries and other leadership positions in the municipal public administration.

Keywords: Leadership, Public Management, Public Organizations.

\section{INTRODUÇÃO}

Os sucessos ou fracassos das organizações estão diretamente ligados à forma pela qual 
elas são geridas. Dessa maneira, surge a necessidade de figuras de referência, seja pelo conhecimento acumulado ou carisma, sejapelo seu lugar na hierarquia. Para Hunter (2006), o desafio atual não é mais apenas gerir as pessoas em busca do objetivo da organização, mas sim influenciá-las para trabalharem entusiasticamente em busca de objetivos comuns, inspirando confiança, deixando de gerir pessoas e passando a gerir com pessoas. Isso posto, essa figura de referência deve se distanciar da imagem obsoleta e prejudicial de um chefe, que busca o tempo todo um funcionário fazendo algo diferente do que ele quer para puni-lo e faze-lo de exemplo para os demais.

Portanto, liderança é um termo comum nas organizações do setor privado, e, juntamente com gestão por competências, inovação, postura empreendedora e outros termos, vem sendo incorporada ao vocabulário da administração pública brasileira, a partir dos anos de 1980 e 1990, quando a administração pública mantinha uma estrutura centralizada, com hierarquias formais e sistemas de controle tayloristas (BRESSER, 1996). Contudo, atualmente há uma evolução da abordagem do serviço público, outrora burocrática, formal, hierárquica, com sistemas de normas rígidos e prevalência da impessoalidade (WEBER, 1978), para uma abordagem gerencial, focada nos resultados e atenta às competências interpessoais.

Para Macarow (1973), líder é aquele que influencia outros a atingirem certos objetivos, através de comunicação interpessoal, sempre de forma objetiva e franca. Bateman e Snell (1998) mostram conceito semelhante e completam: ter visão e comunica-la aos outros é essencial para um grande líder. Empregando este conceito, um líder é capaz não só de influenciar, mas também de estar aberto às discussões com os liderados para encontrar as melhores formas de atingir os objetivos da equipe.

O estudo dos vários estilos de liderança e quais são suas características é necessário para que o gestor público possa alocar o líder certo na área que necessita de um perfil específico, capaz de gerir com pessoas e com uso de competências que auxiliam a equipe a buscar melhor desempenho no atendimento à sociedade. Conforme Monteiro (1991), a liderança não é instituída com uma portaria de nomeação, mas é preciso, além disso, conhecer os diferentes estilos de liderança e qual seu impacto na equipe de trabalho, ou seja, essas ferramentas são essenciais na atual realidade da gestão pública, que busca prover um serviço de qualidade à população.

Considerando que as instituições públicas não devem ter lucro financeiro, a demanda por mais eficiência e resultados nos serviços prestados à comunidade são os objetivos buscados pelos gestores públicos. Com a transparência nos processos de contratação e também na maior participação da população nas decisões, faz-se necessário melhor análise 
daqueles que irão gerir áreas críticas da administração pública. Portanto, faz-se necessário conhecer a área de forma técnica, mas também é importante conhecer o viés político da atuação dos líderes, em especial na gestão pública municipal, que é a mais próxima do cidadão comum.

Desta forma, o conhecimento dos diferentes tipos de liderança e de suas diversas características é importante na escolha dos profissionais que irão ocupar cargos como secretários. Conhecer quais características são necessárias para gerir diferentes pastas irão auxiliar a definição de quem ocupará os postos mais altos na hierarquia da gestão municipal e em quais áreas cada estilo de liderança será mais eficiente.

Diante disso, este trabalho procura buscar respostas para o seguinte problema, a saber: Quais estilos e características de liderança são indispensáveis quando da seleção de secretários municipais?

Partindo, portanto, da análise das características de liderança e do padrão de nomeação para cargos de gestão em diferentes áreas da administração pública municipal, este trabalho tem como objetivo geral identificar e classificar estilos e características de liderança que são vistos como essenciais para nomeação de secretários e coordenadores pelo executivo municipal de cidades do Vetor Norte da Região Metropolitana de Belo Horizonte. São objetivos específicos do presente estudo investigar quais características de liderança são relevantes para a escolha dos secretários, comparar os tipos de liderança mais apontados pelos executivos municipais e detectar quais são mais propensos a ocupar esses cargos na administração pública.

Este estudo se justifica por precisar quais características os chefes do executivo municipal que participaram da pesquisa consideram mais importantes em seus secretários, o que poderá contribuir para próximos processos seletivos de secretários e cargos de liderança das equipes encabeçadas pelos respondentes, tanto permitindo mais objetividade e presteza nas escolhas, quanto criando meios de identificar candidatos que melhor se enquadrem na filosofia de trabalho dos prefeitos ouvidos.

\section{FUNDAMENTAÇÃO TEÓRICA}

\section{$O$ conceito de Liderança}

O termo liderança vem ganhando diferentes perspectivas ao longo do tempo, tanto em no campo acadêmico quanto na aplicação dentro das organizações. Para Benevides (2010), o entendimento de que a liderança seria uma característica que certas pessoas teriam desde seu nascimento vem sendo substituído, após diversos estudos, para um panorama do líder como 
um ser comum e que sua capacidade de liderar dependeria do contexto, do ambiente em que está inserido e de seu desenvolvimento.

Embora existam muitos elementos comuns nas diferentes definições, não há um consenso entre os estudos. Para Hunter (2006), liderança é a capacidade de influenciar pessoas a trabalharem em busca de um objetivo comum, inspirando confiança nos liderados. Já Motta (1997), mesmo concordando que liderança envolve a influência de outros, coloca essa indução como uma força psicológica intencional, que envolve poder e autoridade. Jordão (2002) aponta que o processo de liderar consiste em conduzir as pessoas para que façam o necessário, de livre e espontânea vontade, conseguindo provocar nos liderados o interesse de fazer o que precisa ser feito para alcançar os objetivos.

Maximiano (2000) apresenta outra perspectiva, onde defende que liderar é direcionar colaboradores humanos em prol de finalidades específicas, de forma contínua, em diferentes situações, sempre identificando e empregando valores e motivações, tanto do próprio líder, quanto da equipe de liderados. Essa abordagem apresenta o líder como um ser comum, com conhecimentos e limitações a serem trabalhados no processo para atingir metas da equipe. Para o autor, o líder deve estar inserido na equipe, trabalhando em conjunto, e não como um ser externo que apenas aponta o objetivo e aguarda.

Em consonância, Nez (2008) defende que ser líder é liderar e ser liderado, mantendo ligações interpessoais e focando no trabalho em conjunto, de forma a garantir que os objetivos comuns entre todos, ou os objetivos da instituição, sejam alcançados. É possível encontrar semelhanças entre esse conceito e o apresentado por Sun Tzu (IV a. C.) em sua obra "A Arte da Guerra", em que o autor coloca o líder como aquele ser capaz de induzir os liderados a seguir os mesmos objetivos do líder. Assim, o líder, seja no campo de batalhas ou nas organizações, não impõe sua vontade, mas utiliza o controle através da unidade. Considerando-se que sua influência é natural e espontânea, ele persuade, insinua, provoca e sugere, exercendo um papel imprescindível no desenvolvimento dos membros liderados, ao passo que gerencia e direciona os esforços para que os objetivos sejam conquistados.

Kotter (1997), tem uma abordagem que confronta os termos liderança e gerenciamento, onde o primeiro se dá através das pessoas e da cultura, de forma calorosa e flexível, já o último, age através da burocracia, da hierarquia e é colocado de forma fria e rígida. Dessa forma, pode-se inferir que não deve acontecer uma total separação entre os termos, mas sim um equilíbrio.

Como foi dito, muitas definições são dadas pelos muitos autores que tratam do tema liderança. Cada um com suas pesquisas, apontam para uma descrição que tem em comum o 
viés de que o líder é aquele que deve ser capaz de conduzir a equipe no processo de alcançar os objetivos de forma espontânea. Ele é responsável por influenciar os liderados, provocando criatividade e envolvimento destes em todo processo desenvolvido, com intuito de despertar nos mesmos o sentimento de querer conquistar as metas estabelecidas.

Sendo assim, entende-se que o líder não é apenas um tomador de decisões importantes, mas sim é aquele que indica o caminho e conduz seus liderados a alcançarem o objetivo pretendido pela organização.

\section{Estilos de Liderança}

Identificar o perfil de liderança adotado pelo líder torna possível conhecer como a equipe será conduzida e quais resultados poderão ser conquistados. Vários pesquisadores abordaram e apresentaram diferentes estilos de liderança, não se podendo apontar um melhor ou pior, vez que tal julgamento é situacional, levando em conta variáveis como as atividades a serem executadas e as pessoas a serem lideradas. Contudo, uma teoria que é mais comumente referenciada é a de White e Lippitt apud Possi (2006), que apresenta três estilos de liderança: autocrática, democrática e liberal.

Líder autocrático se caracteriza por determinar diretrizes e técnicas de execução das tarefas sem consultas ao grupo, além de concentrar em si o poder de definir quem assume qual atividade. Ele é inflexível e domina todo processo, podendo gerar mal-estar organizacional. Segundo Camargo (2009), o estilo autocrático está voltado para a produção, na qual o líder diz aos liderados o que devem fazer e como fazer.Neste estilo de liderança, é possível inferir que o poder do líder acontece em virtude de sua posição hierárquica, e que as atividades só se desenvolvem na presença deste, fixando metas, distribuindo tarefas de acordo com seus critérios e tomando as decisões de forma individualizada.

O líder democrático é aquele que provoca o debate na equipe, com intuito de que todos participem na tomada de decisões, e, com carisma, se coloca como um igual no grupo, promovendo bom relacionamento e ritmo de trabalho suave, seguro e de qualidade. $\mathrm{Na}$ liderança democrática, o líder é preocupado com as relações interpessoais e compartilha suas responsabilidades de liderança, envolvendo toda equipe no planejamento e execução das tarefas (CAMARGO, 2009). Desta forma, o poder do líder democrático é atribuído pelos liderados, que estimula a criatividade da equipe e permite que as pessoas possam gerir-se a si mesmas no decorrer das atividades, sendo adequadamente motivadas.

Já o líder liberal, ou Laissez-faire, é aqueleque dá total liberdade para tomada de decisões em grupo ou individuais. Este líder não se impõe e não é respeitado. Tamanha 
liberdade pode passar a impressão que a liderança não existe, pois não há um foco como nos dois estilos vistos anteriormente.Sobre o estilo de liderança liberal, disse Fachada (2003, p. $57)$ :

\footnotetext{
Os liderados têm total liberdade para tomar decisões, quase sem consulta ao líder. Não há grande investimento na função, havendo participações mínimas e limitadas por parte do líder. O grupo é quem decide sobre a divisão das tarefas e sobre quem trabalha com quem. Os elementos do grupo tendem a pensar que podem agir livremente, tendo também desejo de abandonar o grupo. O líder não regula e nem avalia o grupo, a faz alguns comentários irregulares sobre as atividades apenas quando questionado. A produção não é satisfatória, visto que se perde muito com discussões e questões pessoais.
}

Neste estilo, considerado frequentemente como o pior estilo de liderança, não há respeito com o líder e o nível de produção e as relações interpessoais se apresentam inapropriados.

\section{O Líder nas organizações}

O estudo da liderança, seus estilos e impactos causados nas organizações, vem evoluindo seguindo a evolução das próprias instituições. Desde Max Weber, com seu modelo que defendia que, para a organização atingir bons resultados, era essencial o controle burocrático (MAXIMIANO, 2006). Essa formalização contribuiu com um método considerado eficiente na época, porém, por outro lado, tal modelo se preocupava com a autoridade formal, em suas normas e regras rígidas, cravadas em regulamentos.

Com a percepção da necessidade de uma liderança voltada para a quebra dos procedimentos rígidos, burocráticos e mecanicistas de outrora, a partir da década de 1950, tem-se a origem da administração moderna, que busca adaptar e aplicar os antigos e eficientes métodos nas empresas atuais, considerando as variáveis e cenários atuais.

Dessa forma, o papel do líder se torna cada vez mais fundamental diante da organização que ele representa, seja ela pública ou privada. Ele é responsável por conduzir o trabalho dos demais agentes da organização e, ante o exposto, o líder é uma pessoa que é seguida, espelhada, é um modelo para os demais elementos do grupo. A maneira do líder agir e se relacionar com os liderados causa impacto no ambiente organizacional, pois as pessoas vão adotar determinados comportamentos em função da maneira que o líder age.

Por meio dos conhecimentos dos estilos de liderança, pode-se entender que o líder deve-se guiar pelo trabalho em equipe, conduzindo as pessoas e administrar suas diferenças, considerando suas aspirações pessoais, características e objetivos distintos. Portanto, sobre a importância da equipe, Maxwell (2007, p. 331) destaca: 
Em minhas organizações, não tenho funcionários. Tenho colegas. Sim, pago as pessoas e ofereço benefícios a elas. Mas as pessoas não trabalham para mim. Elas trabalham comigo. Trabalhamos juntos para concretizar a visão. Sem elas, eu não posso vencer. Sem mim, elas não podem vencer. Somos uma equipe. Atingimos nossos objetivos juntos. Precisamos uns dos outros. Se não precisarmos, então um de nós está no lugar errado.

Portanto, o líder ocupa uma posição de articulador de talentos e recursos humanos, com a capacidade de encontrar as pessoas certas para executar determinadas tarefas, transmitindo entusiasmo e engajando seus liderados para obter os resultados esperados pela organização.

\section{Liderança no Setor Público}

A grande ênfase em estudos sobre liderança direcionados ao setor privado, gerando uma carência de pesquisas mais criteriosas e amplas sobre o tema na esfera pública, torna a demanda por contribuições teóricas ainda mais relevante. Essa insuficiência de estudos talvez esteja associada à suposição de que o serviço público é um mar burocrático e que as burocracias são regidas por forças que estão além do controle e influência dos líderes (HOOIJBERG e CHOI, 2001).

Apesar de apresentarem características semelhantes aos líderes do setor privado, os líderes da esfera pública se conectam com vários objetivos, ligados à diversas necessidades e interesses que geram dificuldades de se mensurar os resultados de suas ações, enquanto os primeiros tenderiam a ter objetivos mais claros. Além dessas dificuldades, a rotatividade dos líderes públicos, seja por limite de tempo nos cargos, finalização de determinados projetos ou pela simples mudança do executivo municipal. Ademais, deve-se considerar a estabilidade no emprego que é experimentada pela maioria - ou até mesmo a totalidade - de seus liderados, o que pode, em alguns casos, acarretar em impasses nos momentos de criação de novos mecanismos e de intervenções do líder.

A capacidade de pacificar e conciliar conflitos são características que Carbone (1999) cita como mais marcantes em líderes do setor público em relações ao privado. E tal capacidade se faz essencial, haja vista que questões políticas muitas vezes podem criar problemas de gestão para organizações públicas. Um exemplo recorrente é a busca por apoio político quando da candidatura para cargo eletivo, que após a eleição pode resultar em indicações de profissionais para ocuparem cargos de liderança que exijam mais requisitos técnicos do que características políticas, gerando sofrimento à departamentos e servidores sendo geridos por líderes interessados no poder da posição, e não comprometidos com o bom 
resultado da instituição.

O líder deve estar ciente de que ele próprio deve ser um agente de mudança, incentivando-as e facilitando-as. Dessa forma, deve manter-se aberto a novas ideias e inovações, visto que mudanças nas organizações afetam e dependem das pessoas, portanto, a solução dos problemas presentes no setor não depende exclusivamente de alterações na organização, mas também de transformações das pessoas para que a mudança maior aconteça (MARTINS, 2009).

Para Longo (2009), as pessoas são peças-chave para as mudanças, pois têm capacidades para mudar e vontade de fazê-lo, fatores determinantes do sucesso. Dessa forma, a gestão dos recursos humanos deve focar no desenvolvimento de atitudes positivas dirigidas aos planos da instituição pública e na capacitação dos funcionários, para dirigi-los de forma eficaz.

Sendo assim, é entendido que o líder ocupa papel determinante em momentos de mudança. Acerca das mudanças na administração pública municipal, devido a existência de normas e procedimentos engessados, ou devido a cultura relutante à inovação, além da inclinação para uma baixa percepção, por parte de políticos, da relevância da gestão e da liderança eficiente na busca e conquista dos resultados, o líder deve ser agente de mudanças, proativo, comprometido, resiliente e capaz de envolver seus liderados na busca pela prestação de serviços públicos eficientes, trazendo cada vez mais benefícios aos cidadãos e a sociedade.

\section{METODOLOGIA}

A pesquisa que originou o presente artigo se classifica comopesquisa bibliográfica e descritiva, pois busca identificar e analisar fenômenos e fatos presentes na seleção de secretários municipais, além de apontar quais são as características de liderança essenciais no processo de escolha deles, investigando a preferência de estilo de liderança dos prefeitos,em que cada chefe do executivomunicipal forneceu informações sobre o tema.

Os sujeitos do estudo, que por Vergara (2007) são aqueles que forneceram os dados que o autor necessita para realizar a pesquisa, foram os prefeitos em atividade de 11 (onze) cidades do Vetor Norte, da Região Metropolitana de Belo Horizonte, sendo: Capim Branco, Confins, Funilândia, Jaboticatubas, Lagoa Santa, Matozinhos, Pedro Leopoldo, Prudente de Morais, Ribeirão das Neves, Santana do Riacho e São José da Lapa.

Para entender o impactoque as características de liderança têm no processo de escolha do profissional que ocupará cargos de secretários municipais é necessário conhecer o grau de importância que cada uma delas tem no processo dessa decisão. 
Como instrumentos de pesquisa foi utilizado o questionário que, segundo Lakatos e Marconi (2001), é um método de coleta de dados que contém uma série de perguntas que devem ser respondidas por escrito e sem a presença dos respondentes e que busca atender à assoberbada agenda dos gestores. Este questionário foi composto por 10questões fechadas, com questionamentos claros, objetivos e compreensíveis, sem identificar quem respondeu,com indagações que objetivam conhecer o perfil dos respondentes (questões de 1 à 3) e identificar quais características de liderança os prefeitos acreditam ser mais importantes no processo de seleção do secretariado (questões de 4 à 10). No quadro 1 está o questionário.

\begin{tabular}{|c|c|}
\hline 1. & $\begin{array}{l}\text { Qual sua idade? } \\
\text { () Até } 35 \text { anos } \\
\text { ( ) } 36 \text { a } 45 \text { anos } \\
\text { () } 46 \text { a } 55 \text { anos } \\
\text { () Acima de } 56 \text { anos }\end{array}$ \\
\hline 2. & $\begin{array}{l}\text { Grau de escolaridade: } \\
\text { ( ) Fundamental } \\
\text { ( ) Ensino Médio } \\
\text { ( ) Ensino Superior } \\
\text { ( ) Pós Graduação }\end{array}$ \\
\hline 3. & $\begin{array}{l}\text { Liderança é igual a gerenciar? } \\
\text { ( ) Sim } \\
\text { ( ) Não }\end{array}$ \\
\hline 4. & $\begin{array}{l}\text { Quanto à definição de tarefas, o líder deve: } \\
\text { () Determinar as tarefas } \\
\text { () Deixar a divisão de trabalho a critério de cada membro } \\
\text { ( ) Determinar as tarefas em conjunto com todos os membros da equipe }\end{array}$ \\
\hline 5. & $\begin{array}{l}\text { Quanto à participação dos membros na tomada de decisões, o líder deve: } \\
\text { () Fazer orientação todos trabalhos } \\
\text { ( ) Dar liberdade completa ao grupo } \\
\text { ( ) Incentivar a participação ativa com os membros }\end{array}$ \\
\hline 6. & $\begin{array}{l}\text { Sobre a forma de escolha das equipe de trabalho, o líder deve } \\
\text { () Definir quem fará parte de cada equipe } \\
\text { ( ) Permitir que os membros escolhem quem fará parte da equipe } \\
\text { () Definir as equipes de trabalho em conjunto com os membros }\end{array}$ \\
\hline 7. & $\begin{array}{l}\text { Qual deve ser a maior qualidade do líder? } \\
\text { ( ) Ter total controle dos processos de trabalho } \\
\text { ( ) Permitir que a equipe exerça as tarefas sem sua interferência } \\
\text { ( ) Procurar ser um membro da equipe }\end{array}$ \\
\hline 8. & $\begin{array}{l}\text { O que é preciso para liderar uma equipe? } \\
\text { () Saber que sem seu comando os resultados não serão alcançados } \\
\text { ( ) Não tentar avaliar ou regular a execução dos trabalhos } \\
\text { ( ) Dar oportunidades para que todos expressem suas opiniões }\end{array}$ \\
\hline 9. & $\begin{array}{l}\text { Quanto ao poder do líder perante sua equipe: } \\
\text { () Deve prover de sua posição na hierarquia } \\
\text { () Deve ter a impressão de não existir } \\
\text { () Deve ser atribuído pelos liderados }\end{array}$ \\
\hline 10. & $\begin{array}{l}\text { Ao exercer poder de liderança, qual estilo você considera ser ideal? } \\
\text { ( ) Autocrático (Dominante, autocrático) } \\
\text { ( ) Liberal (Compreensivo, aberto) } \\
\text { ( ) Democrático (Popular, flexível) }\end{array}$ \\
\hline
\end{tabular}

Fonte: elaborado pelos próprios autores (2019). 
Para aplicação do questionário foi utilizada a ferramenta Google Docs e o link da pesquisa (https://forms.gle/9i9A1EZXN7ThJBty9)foi enviado por e-mail aos prefeitos dos municípios, após contato prévio por telefone e/ou pessoal, ou seja, o universo é composto pelos prefeitos de cidades do vetor norte da Região Metropolitana de Belo Horizonte e a amostra é composta por 11 prefeitos, e foi escolhida levando em conta aqueles prefeitos que se dispuseram a receber o questionário e responde-lo, conforme contato prévio.

Após compilação, os dados da pesquisa foram consolidados e dispostos em planilhapara fornecer melhor visualização. Seguindo o método quantitativo, a análise de dadosapresenta o padrão de respostas para cada questionamento, com intuito de esclarecer qual grau de importância é dado para cada característica de liderança relevantes quando da seleção dos profissionais que ocuparão cargos de liderança dentro da administração pública municipal das cidades estudadas.Para esse fim, utilizou-se de procedimentos de estatística descritiva.

\section{RESULTADOS E DISCUSSÃO}

$\mathrm{Na}$ aplicação da pesquisa, o intuito é que os respondentes, responsáveis diretos pelas contratações de profissionais a ocuparem cargos de gestão na administração pública municipal, respondessem as perguntas conforme descrição: Este questionário é parte de uma pesquisa conduzida e elaborada pelo Adm. Max Pereira e faz parte do Trabalho de Conclusão do Curso "Especialização em Gestão Pública Municipal”, da Universidade Federal de São João del Rei.Não existem respostas certas ou erradas. Por isso lhe solicito que responda de forma espontânea e sincera a todas as questões.

A tabela 1 procura investigar se os respondentes entendem liderança e gerência como conceitos iguais ou diferentes.

Tabela 1: Percepção sobre a liderança

\begin{tabular}{l|c}
\hline Para você, liderança é igual a gerenciar? & $\%$ \\
\hline ( ) Sim & 27,3 \\
\hline ( ) Não & 72,7 \\
\hline
\end{tabular}

Fonte: elaborada pelos próprios autores (2019).

Os apontamentos da pesquisa mostram que $72,7 \%$ dos respondentes discordam que liderança é igual a gerenciar, no entanto $27,3 \%$ concordam com a afirmativa.Considerando que não houveram dúvidas quanto aos conceitos dos termos, isso mostra que a maior parte dos respondentes entender que há diferenças entre líderes e gerentes.

A tabela 2 identifica, de acordo com os respondentes, qual comportamento deve ser 
adotado pelo líder quanto da definição de tarefas.

Tabela 2: Sobre definições de tarefas

\begin{tabular}{l|l}
\hline Quanto à definição de tarefas, o líder deve: & $\%$ \\
\hline ( ) Determinar as tarefas por seus critérios & 9,1 \\
\hline ( ) Deixar a divisão do trabalho a critério de cada membro do grupo & - \\
\hline ( ) Determinar as tarefas em conjunto com todos os membros da equipe & 90,9 \\
\hline
\end{tabular}

Fonte: elaborada pelos próprios autores (2019).

Para esta questão, a maior porcentagem de respostas foi: 'Determinar as tarefas em conjunto com todos os membros da equipe', com 90,9\%, mostrando que a maioria dos respondentes acreditam que os líderes devem se inserir no grupo, trabalhando em conjunto e não apenas se portar como um ser externo, que apenas aponta o caminho. Enquanto apenas 9,1\% afirmam que o líder deve determinar as tarefas utilizando seus próprios critérios, sem envolvimento dos outros membros.

A tabela 3 demonstra comportamento adotado pelo líder em relação à tomada de decisões.

Tabela 3: Sobre participação dos membros da equipe

\begin{tabular}{l|l}
\hline Quanto a participação dos membros da equipe na tomada de decisões, o líder deve: & $\%$ \\
\hline ( ) Fazer orientações de todos os trabalhos & 36,4 \\
\hline ( ) Dar liberdade completa ao grupo & 18,2 \\
\hline ( ) Incentivar a participação ativa com os membros & 45,5 \\
\hline
\end{tabular}

Fonte: elaborada pelos próprios autores (2019).

Quanto ao processo decisório, 45,5\% dos prefeitos respondentes acreditam que o líder deve incentivar a participação ativa dos membros no processo de tomada de decisões, enquanto $18,2 \%$ acreditam que deve ser dada completa liberdade para que os membros tomem as decisões. Já para 36,4\%, o líder deve fazer orientações para todos os trabalhos. Esta variação de respostas acompanha a grande quantidade de estudos relacionados à liderança, mas a maioria defende que o líder deve fomentar a participação dos membros nas decisões da equipe, dando importância para cada membro e mostrando que toda equipe é capaz de decidir.

A tabela 4 procura mostrar atitudes que o líder deve ter acerca da escolha das equipes de trabalho.

Tabela 4: Sobre a escolha das equipes

\begin{tabular}{l|l}
\hline Sobre a forma de escolha das equipes de trabalho, o líder deve: & $\%$ \\
\hline ( ) Definir quem fará parte de cada equipe & 36,4 \\
\hline ( ) Permitir que os membros escolham quem fará parte da equipe & - \\
\hline ( ) Definir as equipes de trabalho em conjunto com os membros & 63,6 \\
\hline
\end{tabular}

Fonte: elaborada pelos próprios autores (2019). 
Quando perguntados sobre a forma de escolha das equipes de trabalho, 63,6\% dos respondentes afirmaram que o líder deve definir as equipes em conjunto com os outros membros, já para 36,4\% o líder deve ser o responsável pela definição de quem será parte de cada equipe de trabalho.Diante do exposto, é possível inferir que há dificuldade de alguns gestores em conseguir envolver a equipe e se inserir na mesma, trabalhando em conjunto e não apenas apontando o objetivo e aguardando o resultado.

A tabela 5 identifica qual seria, para os respondentes, a maior qualidade de um líder.

Tabela 5: Qualidades de um líder

\begin{tabular}{l|l}
\hline Dentre as opções abaixo, qual deve ser a maior qualidade de um líder? & $\%$ \\
\hline ( ) Ter total controle dos processos de trabalho & 45,5 \\
\hline ( ) Permitir que a equipe exerça as tarefas sem sua interferência & 18,2 \\
\hline ( ) Procurar ser membro da equipe & 36,4 \\
\hline
\end{tabular}

Fonte: elaborada pelos próprios autores (2019).

Para 45,5\% dos respondentes, a maior qualidade de um líder é ter total controle dos processos de trabalho, enquanto 36,4\% acreditam que o líder procurar ser um membro da equipe é qualidade mais importante. Já para 18,2\%, o ato de permitir que a equipe exerça as tarefas sem a interferência do líder é mais importante dentre as opções. Esta questão aponta que os respondentes consideram essencial que os líderes tenham controle de todos processo de trabalho, seja um controle de conhecimento e acompanhamento da execução das tarefas ou defendendo um líder controlador, que acompanha o trabalho de perto.

A tabela 6 exibe a conduta que os respondentes apontam como mais adequada para se liderar uma equipe.

Tabela 6: Liderar uma equipe

\begin{tabular}{l|l}
\hline O que é preciso para liderar uma equipe? & $\%$ \\
\hline ( ) Saber que sem seu comando os resultados não serão alcançados & \\
\hline ( ) Não tentar avaliar ou regular a execução dos trabalhos & \\
\hline ( ) Dar oportunidades para que todos expressem suas opiniões & $100 \%$ \\
\hline
\end{tabular}

Fonte: elaborada pelos próprios autores (2019).

Quando indagados sobre o que é preciso para liderar uma equipe, todos respondentes afirmaram que dar oportunidades para que todos expressem suas opiniões é a opção mais importante. Esta questão evidencia o conceito de liderança que aponta o líder como um comunicador, que mantem as ligações interpessoais e foca no trabalho conjunto para alcançar os objetivos da organização.

A tabela 7 busca identificar a fonte do poder do líder perante a equipe de liderados. 
Tabela 7: Sobre o poder do líder

\begin{tabular}{l|l}
\hline Quanto ao poder do líder perante sua equipe & $\%$ \\
\hline ( ) Deve prover de sua posição na hierarquia & 45,5 \\
\hline ( ) Deve ter a impressão de não existir & 9,0 \\
\hline ( ) Deve ser atribuído pelos liderados & 45,5 \\
\hline
\end{tabular}

Fonte: elaborada pelos próprios autores (2019).

Houve um empate quanto à sua fonte: $45,5 \%$ dos respondentes acreditam que esse poder deve prover de sua posição na hierarquia, e 45,5\% afirmam que deve ser atribuído pelos liderados. Já para 9,0\%, o ideal é que esse poder tenha a impressão de não existir. Nessa questão é evidenciado o equilíbrio entre os conceitos de líder e gerente, onde o primeiro é criado pelas pessoas, de forma flexível e calorosa, e o último é criado pelas burocracia e rigidez hierárquica.

A tabela 8 aponta qual o estilo de liderança é considerado ideal para os respondentes, dentre os estilos mencionados na teoria de White e Lippitt apud Possi (2006).

Tabela 8: Estilo de liderança

\begin{tabular}{l|l}
\hline Ao exercer poder de liderança, qual estilo você considera ser ideal? & $\%$ \\
\hline ( ) Autocrático (Dominante, autoritário) & 9,1 \\
\hline ( ) Liberal (compreensivo, aberto) & 36,4 \\
\hline ( ) Democrático (popular, flexível) & 54,5 \\
\hline
\end{tabular}

Fonte: elaborada pelos próprios autores (2019).

Quando perguntados sobre o estilo de liderança ideal, 54,5\% dos respondentes afirmaram ser o líder democrático, $36,4 \%$ o estilo liberal e $9,1 \%$ apontam o estilo autocrático como o estilo ideal de liderança. Esta pergunta mostra que a maior parte dos respondentes defende que o estilo democrático como o estilo de liderança ideal, sendo aquele que provoca debates e participação de toda equipe, se colocando como membro do grupo e promovendo bom relacionamento e qualidade nos objetivos alcançados.

\section{CONCLUSÕES}

No presente estudo buscou-se identificar e classificar os estilos de liderança que são vistos como essenciais quando da escolha de profissionais que ocuparão cargos de liderança dentro da administração pública municipal, além de comparar quais estilos são mais apontados pelos respondentes e detectar quais estilos são mais propensos a ocuparem tais cargos na gestão municipal dos municípios.

Os resultados encontrados nos permitem inferir que a maioria $(72,7 \%)$ dos prefeitos respondentes entendem que há diferenças entre liderar e gerenciar, apontando uma possível 
diferença quanto ao foco das contratações para os cargos de secretários municipais e equivalentes, haja visto a necessidade presente da atenção às relações interpessoais e o fomento da participação do grupo em todos processos de trabalho, atitudes presentes quando há um líder na equipe e não apenas um gerente-chefe.

Quanto às questões que buscam entender os critérios que os prefeitos utilizam no momento da escolha dos secretários municipais, foram identificadas variáveis que apontam diferenças no padrão de contratações. Ao mesmo momento que quase a totalidade dos respondentes apontam que o líder deve determinar as tarefas em conjunto com todos os membros da equipe, menos da metade $(45,5 \%)$ destes defendem que o líder deve incentivar a participação ativa dos membros no processo de tomada de decisões, além disso, grande parte $(36,4 \%)$ defende que o líder é aquele que deve orientar todos os trabalhos, sem interferências dos membros. Ainda sobre atitudes esperadas do líder a ser contratado, foi constatado que o líder deve escolher as equipes de trabalho em conjunto com os membros do grupo. Essas respostas apontam para um pensamento dicotômico, onde o líder pode ouvir a equipe durante o processo de definição das tarefas, mas a tomada de decisões nem sempre fica a cargo de toda equipe.

Quanto à características que um líder deve ter, a maioria aponta que a maior qualidade do líder é ter total controle dos processos de trabalho, em detrimento de se portar como um membro da equipe. Essa resposta corrobora com o entendimento que nem sempre os prefeitos buscam um líder, mas sim um gerente-chefe.

Quando indagados sobre o que é preciso para liderar uma equipe, todos os respondentes afirmam que é essencial dar oportunidades para que todos os membros da equipe expressem sua opinião, dando liberdade a todo o grupo de falar, questionar, propor ideias e ser criativo. Tal comportamento é presente em equipes que são lideradas e não simplesmente geridas. Para que isso se torne uma realidade no grupo de trabalho, é necessário que o líder seja reconhecido como tal, sem a necessidade de recorrer ao nível hierárquico.

Nesse sentido, quando questionados sobre a fonte do poder dos líderes perante a equipe, houve um empate entre aqueles que acreditam que o poder deve prover da posição hierárquica e aqueles que defendem que o poder do líder deve ser atribuído pelos seus liderados. Tal resultado nos permite depreender que, para alguns respondentes, ter ou não perfil de liderança legitimado pelo grupo de trabalho não é o mais importante, visto que o poder hierárquico foi retificado pelo chefe executivo.Tal dicotomia apresentada em boa parte da pesquisa, onde além da necessidade de um líder que guia a equipe e se coloca como um dos seus membros, também é primordial a presença de um gerente, que dirija a equipe até os 
objetivos da organização, sem permitir liberdades que possam prejudicar os processos de trabalho.

Por fim, a pesquisa levantou a questão de qual estilo de liderança seria o ideal para os respondentes, onde a maioria (54,5\%) aponta para um estilo democrático, com comportamento popular e flexível, e 36,4\% defendem um estilo liberal, compreensivo e aberto, e apenas 9,1\% preferem um líder autocrático, de comportamento dominante e autoritário. Tal questão mostra que, apesar de defenderem estilos de liderança voltados para as relações interpessoais e modernas, os prefeitos ainda sustentam a necessidade de atores que gerenciam as equipes de forma firme, direcionada e objetiva, sem abertura para novas ideias e possibilidades.

Considerando os dados apurados na pesquisa, pode-se concluir que, para o grupo de prefeitos respondentes, é primordial a presença de um equilíbrio entre os estilos de liderança, ora pendendo para o democrático, ora para o autocrático, haja visto a necessidade constante de controlar de forma rígida os processos de trabalho, visando um bom serviço, ao mesmo momento que deve-se estar aberto às ideias e propostas dos membros da equipe. $\mathrm{O}$ profissional que dispõe de características desses dois estilos tende a ser mais bem quisto quando das indicações, seleções e nomeações de secretários e demais cargos de liderança na administração pública municipal.

Sendo assim, em termos de futuras pesquisas, sugerem-se estudos que venham a aprofundar este tema da liderança no âmbito público municipal, em virtude da grande variedade de prioridades, ora focada em boas relações do líder com os liderados, ora voltadas para total controle de todos processos. Ademais, é recomendado que prefeituras estudem a real necessidade de um líder ou um gerente caso a caso, secretaria a secretaria, dado que podem existir peculiaridades em diferentes setores da administração pública que necessitam de maior controle, enquanto outra área clama por mais abertura de pensamento e fomento da criatividade da equipe.

\section{REFERÊNCIAS}

BATEMAN, Thomas S.; SNELL, Scott A. Administração Management: Construindo Vantagem Competitiva. 1ed. São Paulo: Atlas, 1998.

BENEVIDES, V. L. A., Os estilos de liderança e as principais táticas de influência utilizadas pelos líderes brasileiros. Dissertação (Mestrado Executivo em Gestão Empresarial). Rio de Janeiro: Escola Brasileira de Administração Pública e de Empresas. 
2010

BRESSER PEREIRA, L.C. Da administração pública burocrática à gerencial. Revista do Serviço Público, v. 120, n. 1, p. 7-41, jan./abr. 1996.

CAMARGO, Denise de. Psicologia Organizacional. Florianópolis: Departamento de Ciências da Administração. UFSC. CAPES: UAB. 2009.

CARBONE, P.P. Cultura organizacional do setor público brasileiro: desenvolvendo uma metodologia de gerenciamento da cultura. 1999. Disponível em: http://bibliotecadigital.fgv.br/ojs/index.php/rap/article/view/6273. Acesso em 29 junho de 2019.

FACHADA, Maria Odete. Psicologia das Relações Interpessoais. 6 ed. Lisboa: Rumo, 2003. GEISLER, Jill. Como se tornar um ótimo chefe: Aprenda a obter o melhor de sua equipe e criar um ambiente de trabalho positivo. 1. ed. Rio de Janeiro: Sextante. 2013.

HUNTER, James C. Como se tornar um líder servidor: os princípios de liderança de o monge e o executivo. Rio de Janeiro: Sextante, 2006.

JORDÃO, Sônia. A Arte de Liderar:Vivenciando mudanças num mundo globalizado. Belo Horizonte: Tecer, 2002.

KOTTER, John P. Liderando Mudanças. 12.ed.São Paulo: Campus, 1997.

LAKATOS, E. M.; MARCONI, M. A. Fundamentos metodologia científica. 4.ed. São Paulo: Atlas, 2001.

LONGO, E. Francisco. O papel das pessoas na gestão pública. Disponível em: http://www.fdc.org.br/pt/blog_gestaopublica/List/postagens/post.aspx?ID=6. Acesso em $02 \mathrm{de}$ Agosto de 2019.

MACAROW, Frederick G. O que é exigido dos líderes de amanhã. In: LIDERANÇA no trabalho: regras para boa supervisão. 3.ed. Salvador: EDEB, 1973.

MARTINS, Rogério. Liderança criativa: A criatividade como fator de motivação e liderança. Disponível em: http://www.criarh.com.br/Lideranca.doc. Acesso em 22 de julho de 2019.

MAXIMIANO, A. C. A. Introdução a Administração. São Paulo: Atlas, 2000.

MAXIMIANO, A.C.A. Teoria geral da administração: da revolução urbana à revolução digital. São Paulo: Atlas, 2006. 
MAXWELL, John C. O livro de ouro da liderança: o maior treinador de líderes da atualidade apresenta as grandes lições de liderança que aprendeu na vida. Rio de Janeiro: Thomas Nelson Brasil, 2007.

MOTTA, P.R.A ciência e a arte de ser dirigente. 8 ed. Rio de Janeiro: Record, 1997.

MONTEIRO, José A. Qualidade total no serviço público: questionamentos e recomendações segundo os 14 pontos de W. E. Deming. 2. ed. Brasília: QA\&T Consultores Associados, 1991.

NEZ, E. Desenvolvimento de liderança no serviço público. Colider: 2008.

POSSI, Marcus. Gerenciamento de projetos - guia do profissional: aspectos humanos e interpessoais. Volume 2. Rio de Janeiro: Brasport, 2006.

TZU, Sun. A Arte da Guerra. São Paulo: Record, 2006.

VERGARA, Sylvia Constant. Projetos e relatórios de pesquisa em administração.9 ed. São Paulo: Atlas, 2007.

WEBER, Max. Os fundamentos da organização burocrática: uma construção do tipo ideal. In: CAMPOS, Edmundo (org.). Sociologia da burocracia. 4.ed. Rio de Janeiro: Zahar, 1978. 